\title{
Distribution of Polysemes and Homonyms in Scientific Terms that Cause Difficulties in Science Learning in the Korean Language
}

\author{
Eunjeong Yun \\ Science Education Research Institute, Kyungpook National University, 41566, Daegu, Korea
}

Received September 6, 2020; Revised November 25, 2020; Accepted December 6, 2020

\section{Cite This Paper in the following Citation Styles}

(a): [1] Eunjeong Yun, "Distribution of Polysemes and Homonyms in Scientific Terms that Cause Difficulties in Science Learning in the Korean Language," Universal Journal of Educational Research, Vol. 8, No. 12A, pp. 7802 - 7808, 2020. DOI: 10.13189/ujer.2020.082568.

(b): Eunjeong Yun (2020). Distribution of Polysemes and Homonyms in Scientific Terms that Cause Difficulties in Science Learning in the Korean Language. Universal Journal of Educational Research, 8(12A), 7802 - 7808. DOI: 10.13189/ujer.2020.082568.

Copyright $\mathrm{C} 2020$ by authors, all rights reserved. Authors agree that this article remains permanently open access under the terms of the Creative Commons Attribution License 4.0 International License

\begin{abstract}
Science is not only a field for scientists to attain proficiency but also constitutes a field about which the general public should possess some basic knowledge. In this study, we analysed scientific terms with multiple meanings as one of the main factors that causes difficulties in students' science learning. We also inquired as to how many of these terms are included in the total scientific terms and the extent to which they are used in school education in South Korea. We collected those scientific terms in the field of Korean science, made a list of them and extracted polysemes and homonyms from the Standard Korean Language Dictionary. In addition, we extracted scientific terms used in middle and high school science textbooks and examined the ratio of polysemes and homonyms. The study found approximately 10,000 polysemes and 10,000 homonyms from over 380,000 types of scientific terms in Korea, and out of a total of 2,504 scientific terms extracted from secondary school science textbooks, about 900 (40\%) were polysemes or homonyms.
\end{abstract}

Keywords Scientific Terminology, Polysemes, Homonyms, Science Learning

\section{Introduction}

Science has come a long way since Newton in the $17^{\text {th }}$ century. Accordingly, numerous scientific terms have been coined in the scientific field. It is not only the quantity of terms that has increased but also the quality of terms, with the hierarchy of concepts having gradually intensified. Although the quantitative and qualitative expansion of these scientific terms has served a positive role in promoting the academic development of experts, it has also become a factor that adds to the difficulty in learning science for students [1],[2],[3],[4]. In general, the difficulty of learning scientific terminology in students comes from the hierarchy, complexity and novelty of scientific concepts. However, conversely, the admixture of familiar scientific terms with everyday language could also be a major obstacle to learn science. The reason is because scientists coin new terms that correspond to new theories and concepts but sometimes add an extended meaning to everyday words for new concepts. Even when a new term is created in science, it is occasionally laden with a new mundane meaning because of its usage and popularization in everyday life. The following examples illustrate scientific terms that retain two different meanings: the scientific and the everyday.

In space, there is no gravity.

I don't think you understand the gravity of the situation.

Teachers aren't allowed to use force in the classroom. He joined the police force right after graduating.

You can't force her to make a decision.

It equals the force of gravity pushing down on it. 
Careful teaching of vocabulary with multiple meaning such as homonyms or polysemes is also an important issue in the area of general language education. In particular, because the meaning of words with multiple meaning is determined by context within the sentence, it is necessary to use specific strategies for teaching them [5]. However, in the field of science education, there have been no active studies with scientific terms or scientific terms themselves with multiple meanings [6]. Considering the importance of science education in our society [7] and the importance of teaching of scientific terms [1], [2], [4], it is necessary to study scientific terms in more depth.

\subsection{Difficulties due to Scientific Terms with Multiple Meanings}

Previous studies have emphasised that scientific terminology, when mixed with everyday meanings, has a negative influence on students' science learning [8],[9],[10],[11],[12]. The meaning of a word is determined in the context that is connected to another word, object and situation [13]. Therefore, when a new word is learned, it is recognised in connection with the conte $\mathrm{xt}$ of other words, objects, situations, etc., that learners are already familiar with [14]. In the case of scientific terms with both everyday and scientific meanings, it is considerably likely that students are already used to the everyday meaning of those terms in their daily lives. Thus, when students come to a science class, it is possible that they may conflate the scientific terms that are associated with other words in the context of everyday lives. This connection creates an obstacle to their understanding of the scientific meaning of those terms in science classes [14]. In addition, while the scientific meaning of terms is confined to science classes at school, the everyday meanings of those terms are encountered in everyday lives far more frequently, making it difficult for the scientific meaning to be retained. Therefore, those who teach science should pay particular attention to scientific terms that have both a scientific and an everyday meaning. Teachers should be able to make a distinction between terms that have scientific and everyday meanings and those that do not and reflect this distinction in their teaching strategy [12]. However, a review of most previous studies indicates that such studies only highlight some cases in which everyday and scientific meanings are mixed, and it is difficult to find research on the number of scientific terms in existence and the characteristics that they possess. Hence, the present study aimed to examine how many scientific terms connote multiple meanings, how many of such terms are used in school education and what the morphological characteristics of these terms are.

\subsection{Theoretical Background of Polysemes and Homonyms}

A 'polyseme' is a word that implies more than one meaning; 'homonyms' are two or more different words that use the same pronunciation and spelling [15],[16]. Consequently, from the language user's perspective, polysemes and homonyms may seem similar in that a single word has multiple meanings. Furthermore, some scholars occasionally use polysemes and homonyms without making distinction [17], and in some cases, the boundaries between the two are blurred. Nonetheless, because polysemes and homonyms are distinctly defined grammatical concepts, they were analysed separately in this study. However, to interpret the results, the two cases are not treated differently from learners' perspectives.

The issues of difficulties with polysemes and homonyms are not limited to scientific terms. Discussions on these words in relation to common language acquisition and understanding have also been underway for a long time. The meaning of word with multiple meanings could be determined by the context in which they are used in sentences or in a communication. Therefore, to process the meaning of the word contained in the sentence, one must know what the individual word means and interpret it by selecting the appropriate meaning out of the various meanings involved [18]. To address the meaning of polysemes or homonyms in a sentence, it is necessary to identify the associations of the information entered and ensure that the meaning can be addressed effectively by strengthening activation levels of appropriate meanings and suppressing unnecessary y meanings rapidly [19]. Multiple meanings of words are activated automatically and unconsciously in mind. If unnecessary meanings continue to affect the process of reading the sentence, it could lead to difficulty in understanding the entire meaning of sentence. Consequently, words with multiple meanings require more complex and various steps of cognitive process than words with a single meaning. In practice, individuals who are less proficient in reading comprehension have been reported to have a poor ability in suppressing unnecessary information with respect to the multiple meanings that are activated in the process of understanding sentences [20]. Such individuals also find it difficult to disregard non-contextual meanings despite knowing all the meanings of the polysemic word [21]. In case of students, they are also found to make judgement errors in terms of processing polysemes regardless of their proficiency in reading [21]. 
Most students have difficulties in reading scientific language than everyday language [22],[23]. Thus, the difficulty encountered with polysemes and homonyms can be a bigger issue when reading scientific language. Therefore, it is necessary to conduct research on scientific terms with multiple meanings and explore educational strategies for the same in an active manner.

\section{Research Methodology}

\subsection{Scientific Terminology Collection}

In Korea, there is no single, standardised list of technical terms. Therefore, we extensively collected scientific terms from the glossaries published by various academic groups in the field of science, the list of words that marked as scientific terms in the Standard Korean Language Dictionary and terms used in elementary, middle and high school science textbooks and integrated them into one list. As a result, 385,782 types of scientific terms were collected, excluding overlapping terms, and were subjected to analysis.

\subsection{Extraction Polysemes and Homonyms}

The extraction polysemes and homonyms was derived from the Standard Korean Language Dictionary published by the National Institute of Korean Language in Korea. The aforementioned source is a general-purpose dictionary and Korea's only normative dictionary on Korean writing.

First, words were categorised as polysemes when two or more meanings existed in words listed as single headings in the Standard Korean Language Dictionary. An example of a polyseme with two meanings is as follows:

\section{가속도 (noun)}

1) The increasing speed during procession or the rate at which things change as they progress

2) (physics) The rate of change in velocity over unit time

Two or more words with the same form listed in the Standard Korean Language Dictionary were categorised as homonyms. For the terms collected from the dictionary, all numbered words could be categorised as homonyms because these were differentiated by the provision of numbers after the words. An example of a homonym with three words of the same form is as follows:

부토 ${ }^{1}$ (noun) A handful of earth; grave

부토 ${ }^{2}$ (noun) (earth science) Dark brown fertile soil containing more than $20 \%$ of corrosive substances

부토 ${ }^{3}$ (noun) To dig up soil or sand; or the soil or sand

The list of extracted polynomials and homonyms was compared with the list of scientific terms prepared in 2.1. Automatic checks were made using a computer, and only identical cases were extracted. These extracted terms were regarded as scientific terms with multiple meanings.

\subsection{Analysis of Science Textbooks of Secondary School}

This study investigated the science textbooks of secondary schools to determine the percentage of polysemes and homonyms in scientific terms that students learn through school education. Six science textbooks published by three publishers for middle school and high school $1^{\text {st }}$ grade were used in the analysis. On the basis of approximately 380,000 scientific terms, the scientific terms used in the six textbooks were extracted; subsequently, these terms were compared to the list of polysemes and homonyms of 2.2 .

\subsection{Characteristics of Scientific Terms with Multiple Meaning}

To identify the characteristics of scientific terms with multiple meanings, the number of meanings and syllables were analyzed. Looking at the number of meanings can provide information on how large the semantic burden will be on students learning multiple meanings. The number of syllables provides information on which of these scientific terms have distinguishable forms.

\section{Results and Argument}

\subsection{Ratio of Polysemes and Homonyms among Scientific Terms}

A total of around 380,000 types of scientific terms were collected from various sources. Among these, approximately 100,000 words $(27 \%)$ were listed in the general-purpose Korean dictionary for the public. These 100,000 terms correspond to relatively accessible terms for the general public with high school education, and it can be inferred that these terms are basic concepts in each field of science. The remaining 280,000 scientific and technical terms, after excluding the aforementioned 100,000 terms, are likely to be more specialised terms that are difficult for the general public to access. In particular, the fact that some 280,000 terms are not listed in the general-purpose dictionary means that it may be difficult for the general public to search for the exact definition of these terms. In addition, it means that these words are not used routinely nor have any everyday meaning. Therefore, the 280,000 terms that were not found in the general-purpose dictionary were excluded from the analysis of polyseme and homonym terms that are of interest to this study.

Among the 102,263 scientific terms listed in the general-purpose dictionary, 86,766 were simplexes with single meaning, accounting for $22.5 \%$ of the scientific terms and $84.8 \%$ of the general-purpose dictionary entries. 
These can be regarded as adhering to the basic function of terminology, i.e. a term refers to only one meaning for one form. However, the remaining 15,497 terms had both everyday and scientific meanings at the same time, and it is likely that this has the potential to cause confusion for students learning the terms. Of the 15,497 terms, 11,121 were found to be homonyms, 9,767 were polysemes and 5,391 were both homonyms and polysemes (Table 1).

Table 1. Distribution of terms

\begin{tabular}{|c|c|c|c|c|}
\hline \multirow{2}{*}{} & \multicolumn{3}{|c|}{ Total Scientific Terms (N=385,777) } \\
\cline { 2 - 5 } & $\begin{array}{c}\text { Terms Not Listed } \\
\text { in the } \\
\text { General-Purpose } \\
\text { Dictionary }\end{array}$ & Simplex & Polyseme & Homonym \\
\hline Counts & 283,514 & 86,766 & 9,767 & 11,121 \\
\hline $\begin{array}{c}\text { Ratio } \\
(\%)\end{array}$ & 73.5 & 22.5 & 2.5 & 2.9 \\
\hline
\end{tabular}

\subsection{Ratio of Polysemes and Homonyms among Scientific Terms Used in Science Textbooks}

In total, 2,504 scientific terms were extracted from seventh- and tenth-grade science textbooks. Of these terms, 335 , or $13.4 \%$, were not listed in the general-purpose dictionary. Ideally, all scientific terms used in science textbooks under college level should be listed in the general-purpose dictionary. The existence of terms that are not registered in the general-purpose dictionary can mean either that the dictionary does not fully reflect the scientific terms used in science textbooks under the college level or that the authors of science textbooks have used excessively advanced terms. Further follow-up studies are required to analyse where such terms belong with respect to the two possibilities and to identify and address the potential problems thereof.

Simplexes used only for one meaning accounted for $1,261(50.4 \%)$ among the 2,169 scientific terms listed in the general-purpose dictionary. Of all the scientific terms used in science textbooks, 908 were found to have more than two meanings, except for the terms not listed in the general-purpose dictionary and simplexes. Among these, 635 were homonyms, 698 were polysemes and 425 were both polysemes and homonyms (Table 2). Scientific terms that have both scientific and everyday meanings could cause difficulties in learning for students. Of the 2,504 terms, 908 terms, that is, nearly $40 \%$, can be considered a large percentage of the source of difficulty from the perspective of a scientific learner. Students are generally exposed to the scientific meaning of these terms through science classes. However, because the time of schools' science classes is limited, students are likely to encounter the everyday meaning of scientific terms in their daily lives with higher frequency. Therefore, scientific terms with multiple meanings are tricky to learn because of the high frequency of everyday use that students get used to after learning, as well as the difficulty involved in correctly acquiring scientific meanings due to their mixed usage of everyday meanings.

Table 2. Distribution of terms used in science textbooks

\begin{tabular}{|c|c|c|c|c|}
\hline \multirow{2}{*}{} & \multicolumn{4}{|c|}{ Terms Used in Science Textbooks $(\mathrm{N}=2,504)$} \\
\cline { 2 - 5 } & $\begin{array}{c}\text { Terms Not } \\
\text { Listed in the } \\
\text { General-Purpose } \\
\text { Dictionary }\end{array}$ & Simplex & Polyseme & Homonym \\
\hline Counts & 335 & 1,261 & 698 & 635 \\
\hline Ratio(\%) & 13.4 & 50.4 & 27.9 & 25.4 \\
\hline
\end{tabular}

Table 3 is an example of a scientific term that is both a homonym and a polyseme. The scientific term '결정' presented in the Table 3 entails three homonyms, two of which are polysemes with two meanings each. The first meaning of the second homonym is the scientific meaning of '결정', and it becomes a scientific term only when used in this meaning.

\subsection{Distribution of Meaning in Scientific Terms with Multiple Meanings}

We examined the number of different meanings that a scientific term connotes. The results showed that there were 2-45 homonyms with one scientific term. After the distribution of terms by the number of homonyms, there were 10,458 scientific terms with 2-9 homonyms in most cases and 582 scientific terms with 10-19 homonyms. Scientific terms with more than 20 homonyms have gradually decreased (Table 4). For polysemes, the number of meanings that a scientific word had as a polyseme was found to be a minimum of 2 and a maximum of 24 . Particular attention should be paid to the fact that there are scientific terms with more than 20 or 40 definitions rather than the distribution of the most common number of scientific term definitions per word. The difficulty in teaching students the exact meaning of scientific terms that have such diverse meanings and the education strategies to be employed should also be considered.

Table 3. An example of a scientific term that is both a homonym and a polyseme

\begin{tabular}{|c|c|c|c|}
\hline Terms & Homonym & English translation & Meaning \\
\hline \multirow{3}{*}{ 결정 } & 결정 ${ }^{1}$ & Decision & $\begin{array}{l}\text { 1. Defining behaviour or attitude clearly } \\
\text { 2. Court ruling }\end{array}$ \\
\hline & 결정 ${ }^{2}$ & Crystal & $\begin{array}{l}\text { 1. (chemistry) Atoms, ions and molecules arranged according to a regular set of } \\
\text { rules, and the appearance surrounded by several planes in a symmetrical } \\
\text { relationship, forming a regular, well-defined shape, or such a substance } \\
\text { 2. Efforts to achieve rewarding results or to speak figuratively of the results }\end{array}$ \\
\hline & 결정 ${ }^{3}$ & Decide & Etymon of '결정하다 (making decision)' \\
\hline
\end{tabular}


Table 4. Number of meanings that a scientific term connotes

\begin{tabular}{|c|c|c|c|c|c|}
\hline & $\begin{array}{c}\text { More than 2 } \\
\text { Less than 10 }\end{array}$ & $\begin{array}{c}\text { More than 10 } \\
\text { Less than 20 }\end{array}$ & $\begin{array}{c}\text { More than 20 } \\
\text { Less than 30 }\end{array}$ & $\begin{array}{c}\text { More than 30 } \\
\text { Less than 40 }\end{array}$ & More than 40 \\
\hline Homonym & 10,458 & 582 & 62 & 16 & 3 \\
\hline Polyseme & 12,762 & 32 & 3 & 0 & 0 \\
\hline
\end{tabular}

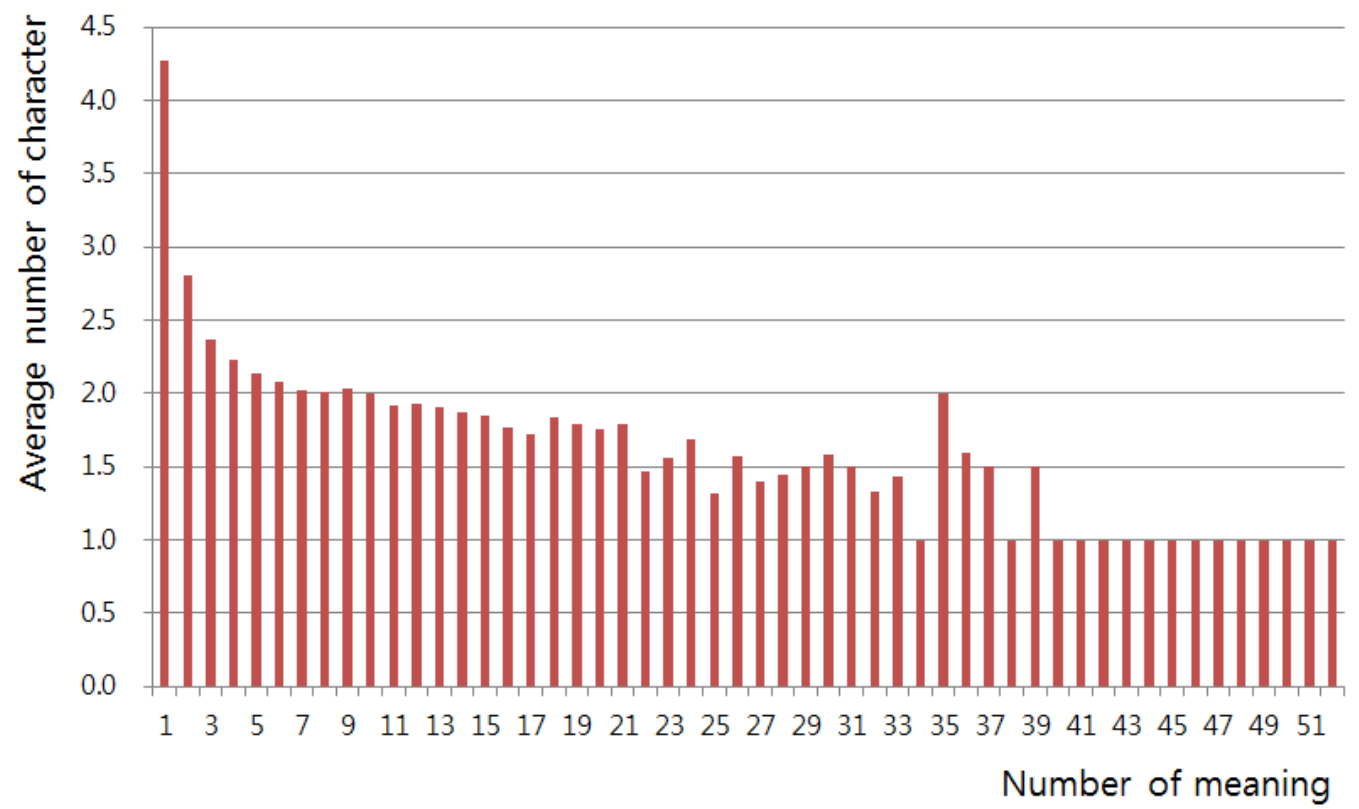

Figure 1. Average number of characters according to the number of meanings

\subsection{Syllables of Scientific Terms with Multiple Meanings}

The number of syllables in scientific terms with multiple meanings was analysed in this study. All the meanings of one scientific term without distinction between polysemic and homonymic terms were searched, and the average number of syllables in scientific terms with the same number of meanings was calculated. Results showed that the more significant the overall number of definitions, the lower the average number of syllables was (Figure 1). This shows that on average, words with fewer syllables are used in a wider variety of meanings, whereas words with more syllables have fewer meanings. A statistical check of the correlation between the number of meanings and the number of syllables shows that the Pearson's $r$ value has a significant correlation of -.30 . In Korean, a syllable, when it is formed, corresponds to the syllable when it is pronounced. In other words, if a word is expressed as three letters, its pronunciation also has three syllables. Therefore, the result of this study, i.e. the smaller the number of syllables, the more diverse is the meaning, is consistent with the result of [13], who finds that there are many extensibility or homonymic phenomena in monosyllabic words. 


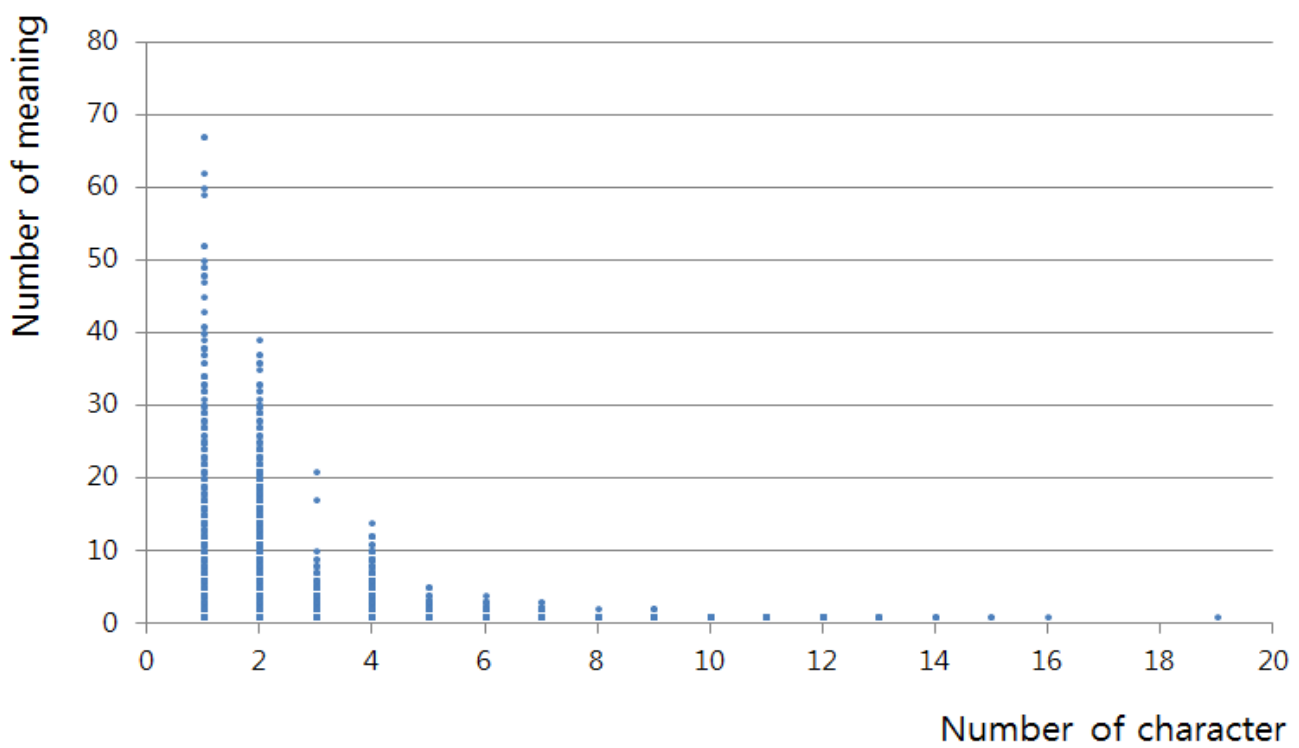

Figure 2. Number of meanings according to the number of syllables in the term

The scatterplot of the number of meanings according to the number of syllables in the term is given in Figure 2. Monosyllabic words with one syllable are evenly distributed from having a single meaning to having more than 60 meanings. It also shows that the number of definitions decreases as the number of syllables increases. Up to nine syllables, two or more meanings were found and all terms with 10 or more syllables are found to have single meaning. In other words, in Korean scientific terms, it can be confirmed that 10 syllables or more do not have an extended meaning or homonymic phenomenon.

\section{Conclusions and Suggestions}

The study investigated the ratio and characteristics of polysemes and homonyms in scientific terms. Among all the scientific terms analysed, the proportion of polysemes and homonyms accounted for approximately 4\%. However, we found that polysemes and homonyms accounted for more than $40 \%$ of the scientific terms used in the science textbooks of secondary school. This result demonstrates that the polysemy of scientific terminology can be a huge obstacle in science learning. This is the reason many students learning science find it difficult to understand the topics, and this obstacle results in their failing to grasp the meaning of the scientific terms in such topics. To address these issues, more in-depth studies of scientific terms with multiple meanings should be conducted, and the corresponding educational strategies should be studied.

The number of meanings under scientific terms corresponding to polysemes and homonyms was found to be $2-9$ on average, and this was most often the case. However, there were hundreds of scientific terms with more than 10 different meanings, and polysemes with more than 20 meanings and homonyms with more than 40 definitions were also found. A technical term is essentially a word that is used in a field of expertise. However, this is an era in which technology is increasingly becoming closely related to our lives and the scientific literacy of the general public is becoming further emphasised. It is necessary to analyse the meaning and value of scientific terms that are overly multi-layered and devise a way for students and the general public to correctly distinguish and acquire the scientific meanings of these terms.

In addition, the fewer the number of syllables, the more the meanings were. The more the number of syllables, the fewer the meanings were. In scientific terms with more than 10 syllables, there was no polysemy. This morphological feature may appear because it is difficult to have polysemy if several existing scientific terms are combined to create a new term. Moreover, when an everyday word with a relatively low average number of syllables is given a scientific meaning, the phenomena of multiple meanings can follow naturally.

Finally, the present study was conducted on Korean words. However, as mentioned in the introduction, the polysemy of scientific terminology and the resulting problems are also common in other countries and different languages. Therefore, those countries as well as English-speaking countries should select and conduct research on distinctive scientific terms by employing an analysis similar to the one used herein.

\section{Acknowledgments}

This work was supported by the Ministry of Education of the Republic of Korea and the National Research Foundation of Korea (NRF-2017S1A5B5A02025954). 


\section{REFERENCES}

[1] Groves, F. H. "A longitudinal study of middle and secondary level science textbook vocabulary loads". School Science and Mathematics, vol. 116, no. 6, pp. 320-325, 2016. https://doi.org/10.1111/ssm.12183

[2] Miller, J. "Teaching refugee learners with interrupted education in science: Vocabulary, literacy and pedagogy". International Journal of Science Education, vol. 31, no. 4, pp. 571-592, 2009. https://doi.org/10.1080/0950069070174461

[3] Wilson, E. O. "Consilience: The Unity of Knowledge", Random House, 1998.

[4] Yager, R. E. "The importance of terminology in teaching K-12 science". Journal of Research in Science Teaching, vol. 20 , no. 6 , pp. $577-588,1983$. https://doi.org/10.1002/tea.36 60200610

[5] Richards, J. C. "The role of vocabulary teaching". TESOL Quarterly. vol. 10, no. 1, pp.77-89, 1976.

[6] Yun, E., \& Park, Y. "Comparison of the usage of the science terminology 'Force' in science and everyday languages". New Physics: Sae Mulli, vol. 66, no. 4, 460-467, 2016.

[7] Kurniawan, D. A., Asrial, S., Salsabilah, W. S., Kurniawati, E. F., Anandari, Q. S., Perdana, R., Lumbantoruan, A., Nasih, N., Samosir, S. C., \& Dewi, U. P. "Ethnoscience Investigation in Primary Schools: Impact on Science Learning", Universal Journal of Educational Research, vol. 7, no. 12 , pp. 2789-2795, 2019. DOI: 10.13189/ujer.2019.071 229 .

[8] Bennet, S. C. "Teaching and Learning Science". Continuum, 2003.

[9] Itza-Ortiz, S., Rebello, N. S. \& Zollman, D., \& Rodriguez-Achach, M. "The vocabulary of introductory physics and its implications for learning physics". The Physics Teacher. vol. 41, no. 6, pp. 330-337, 2003. https://doi.org/10.1119/1.1607802

[10] Lemke, J. "Talking Science”. Ablex, 1990.

[11] Rinche, K. "It's rather like learning a language: Development of talk and conceptual understanding in mechanics lessons". International Journal of Science Education, vol. 33, no. 2, pp. 229-258, 2011. https://doi.org/10.1080/09500691003615343
[12] Song, Y., \& Carheden, S. (2014). "Dual meaning vocabulary words in learning chemistry". Chemistry Education Research and Practice, vol. 1, pp. 128-141, 2014. https://doi.org/10.1039/C3RP00128H

[13] Wittgenstein, L. "The Blue and Brown Books" Blackwell, 1958.

[14] Sternberg, R. J. \& Ben-Zeev, A. "Complex Cognition: The Psychology of Human Thought." Oxford University Press, 2001.

[15] RHCD "Random House College Dictionary". Random House, 1975.

[16] Ulmann, S. "Semantics: An Introduction to the Science of Meaning". Blackwell, 1962.

[17] Palmer, F. R. "Semantics". Cambridge: Cambridge University Press, 1981.

[18] Tabossi, P., \& Zardon, F. "Processing ambiguous words in context". Journal of Memory and Language. Vol. 3, pp. 359372, 1993. https://doi.org/10.1006/jmla.1993.1019

[19] Gernsbacher, M. A. \& Faust, M. "The mechanism of suppression: A component of general comprehension skill". Journal of Experimental Psychology. Learning, Memory, and Cognition. vol. 17, pp. 245-262, 1991. https://doi.org/10.1037/0278-7393.17.2.245

[20] Gernsbacher, M. A., \& Robertson, R. R. W. "Reading skill and suppression revisited". Psychological Science, vol. 6, pp. 165-169, 1995. https://doi.org/10.1111/j.1467-9280.1995.tb 00326.x

[21] Ko, S., Choi, K. S., \& Hwang, M. "Comprehension of ambiguous words in children with poor reading comprehension". Korean Journal of Communication Disorders. vol. 15, pp. 348-356, 2010.

[22] Chall, J. S., Jacobs, V. A., \& Baldwin, L. E. "The Reading Crisis: Why Poor Children Fall Behind”. Harvard University Press, 1990

[23] Rupley, W. H., \& Slough, S. "Building prior knowledge and vocabulary in science in the intermediate grades: Creating hooks for learning". Literacy Research and Instruction, vol. 49, no. 2, pp. 99-112, 2010. https://doi.org/10.1080/193880 70902780472 